Original Research Paper

\title{
Design and Modeling the Prosthetic Foot from Suitable Composite Materials
}

\author{
Hasan Saad Mohammed and Jasim Mohammed Salman \\ Al-Kunooze University College, Medical Laboratories Techniques, Basra, Iraq
}

Article history

Received: 03-06-2020

Revised: 07-07-2020

Accepted: 09-09-2020

Corresponding Author: Hasan Saad Mohammed

Al-Kunooze University

College) Medical La oratories

Techniques, asra, Iraq

Email: bhasansaad1990@Kunoozu.edu.iq

\begin{abstract}
This work concerns developing a composite material, which can be used in manufacturing prosthetic feet with a reasonable cost and satisfying mechanical properties. The characteristics were investigated by mechanical tests of tensile properties and Charpy impact strength. The study of date palm wood and its effects on the mechanical properties of polyethylene have received little attention. It was found that Young's modulus of forty percent high density polyethylene (HDPE) filled with sixty percent of Date Palm Wood (DPW), significantly increased to eighty percent compared with pure HDPE. Moreover, the yield and ultimate stresses were improved, which was approximately two times higher than that observed for pure HDPE; the elongation at break and impact energy were decreased significantly. The characteristics exhibited by prosthetics compared to those of a human foot were investigated further. The analytical section presents the results of the static analysis by numerical methods (Finite Element method FEM), ANSYS Work bench 14 and experimental methods. Thus, the new foot was designed and the dorsiflexion was measured. Overall, the non .articulation of this type of foot is compared against Solid Ankle Cushion Heel (SACH) foot by cost and weight, so that the cost of the non .articulated foot is lower than that of the other by about sixty percent. We also found the new weight is lighter than that of by about two percent. The new model of prosthetic foot has better characteristics, which includes foot life cycle $\left(7.5^{\circ}\right.$ and $\left.1,049,135\right)$ respectively when compared with the other $\left(6.4^{\circ}\right.$ and 896213$)$ respectively.
\end{abstract}

Keywords: Energy Absorption, Impact Test, Polymer, Prosthetic Foot, Tensile Test

\section{Introduction}

Recently, there have been several researchers that have studied prosthetic feet designed and manufactured from polyethylene presented by (Kadhim, 2007). The foot is one of the most complicated structures of the human body; it offers an extremely high degree of stability and activity and it not only bears the weight of the whole body, but has multi. functions such as extension, compression, tortuosity, bouncing, shock absorption and friction described by (Zhang et al., 2013). Current prosthetic designs provide a wide range of choices for below .knee amputees. The appropriate choice of prosthesis can significantly improve the comfort and performance of the patient. Most of the currently available prosthetic ankles, however, do not provide enough energy to propel the body forward studied by (Zeng, 2013); high. Density Polyethylene (DPE) made by low. Pressure methods. In this method, pure ethylene polymerized at a pressure of about 50 atmospheres and temperature between 60.200 Celsius in the presence of the Zeigler Natta catalyst system and supported oxide catalyst (George, 1984). Such polymers are over ninety percent crystalline, more linear compared with low density type and had a density above 0.95 $\mathrm{g} / \mathrm{cm}^{3}$ (Ogah and Afiukwa, 2012). Several researchers have studied composites by preparing polymeric matrices from date palm fibers. The fibers prepared from the date palm are important to making these prosthetics affordable, especially in countries in which date palm tree production is high (AlMaadeed et al., 2012). The mechanical and thermal properties of HDPE and PS matrices were tested reinforced with powder from date palm pits (AlMaadeed et al., 2012). The 
mechanical properties of composites were based on their Linear Low. Density Polyethylene (LLDPE) blended with Date Palm Wood powder (DPW); High .Density Polyethylene (HDPE) mixed with LLDPE lends with DPW. The mechanical properties were determined in the tensile and impact energy to utilize and apply the best properties on the new design of prosthetic foot.

This study used new blends of (HDPE and DPW). In addition, the new prosthetic foot has been tested for stress and strain by ANSYS Work bench. 14. The fatigue and dorsiflexion tests have been thorough.

\section{Experimental Works}

A sensitive electronic read. Out weighing machine, Italy 1700 Model was used to measure a $100 \mathrm{~g}$ of each lend portion of the LLDPE and HDPE pellets respectively. The lend ratios obtained by mixing LLDPE and HDPE resins. Where $\mathrm{w}$ is a weight of a mass of blends in grams. Each of the blends was pulverized, using a mechanical lender to ensure thorough mixing. The blended composition was charged into an injection machine. The following operating conditions: Die.head temperature of $183+10 \mathrm{C}$ and 120 bars. The lend composition was then passed through the die head orifice of the injector, which determines the thickness of the blown films.

\section{Preparation Specimen}

In order to prepare the prosthetic, there should be a mold made of iron, with the dimensions of $20 \times 17.5$ $\mathrm{cm} \times 5 \mathrm{~mm}$. It was made by using ASTM D638 and Surf-cam program and CNC milling machine Model XK 7124 with feed rate 1000 and speed relative to the blend ratio. DPW requires higher speed than HDPE to avoid to Peels or bulge.

\section{Results and Discussion}

\section{Mechanical Properties of HDPE and DPW Blends}

In this part, we characterize the mechanical properties of the composites tested in the tensile mode at room temperature $\left(25^{\circ}\right)$ in a bent position. Table 1 , shows the effect of the additive of DPW on the mechanical properties of HDPE blend, tensile strength at yield, ultimate stress, modulus of elasticity and impact energy.

However, this paper's focus is on the study of properties to design a prosthetic foot from new available and low cost material. Therefore the purpose of the use of HDPE reinforced with DPW is to get the best mechanical efficiency that when mixing HDPE (40 g) with DPW (60 g) increases the yield of stress from 18 $\mathrm{MPa}$ to $45 \mathrm{MPa}$ and ultimate stress from $26 \mathrm{MPa}$ to 50 $\mathrm{MPa}$; an increase of Young's modulus from 1.1 GPa to
1.8 $\mathrm{GPa}$. According to the values taken from the impact test, we can observe decreases in the energy impact. To reduce the cost of the materials used, Recycled Linear Low .Density Polyethylene (RLLDPE) was blended with Date Palm Wood powder (DPW) (Mariam et al., 2014) Ma. molecules are important for all strength properties of polyethylene. Hence, the increasing concentrations of LLDPE introduced tie molecules into the polymer blend.

\section{The Stages of Preparing the New Prosthetic Foot}

1- Drawing the shape in AutoCAD program, then send to ANSYS Work bench to analyze the models of prosthetic foot

2- Sculpting the general shape

3- Casting a negative mold from metal

4- Modifying the negative mold

5- Arrangement of the mold inside the injection machine

6- Preparing the granule of polyethylene in machine cone and adjusting temperature $\left(200^{\circ} \mathrm{C}\right)$, pressure and time of injection. The injection machine contains four heat zones, first heater is $\left(80^{\circ} \mathrm{C}\right)$ and fourth heater is $\left(300^{\circ} \mathrm{C}\right)$ for the blend of HDPE and DPW. The composite materials have been taken $300^{\circ} \mathrm{C}$. This temperature increases gradually

7- Injecting the hot mixture of composite materials granule inside the mold. The injected foot is visible in Fig. 1

\section{Numerical Analysis Results}

\section{Static Analysis}

The fatigue and static properties of two models of non-articulated foot investigated using finite element method (ANSYS 14).

The aim of this analysis is to investigate the stresses and deformations of a clamped non-articulated foot with force after assuming that this value is the average of applied load ( $86 \mathrm{~kg}$ or $846 \mathrm{~N}$ ).

Figure 5 and show the Von-Misses stresses distribution along the non-articulated foot, at the deformation of the above mentioned foot and VonMisses where the stress contours at the toe off phase with force of $(846 \mathrm{~N})$ respectively.

Table 1: Mechanical properties of blends at $25^{\circ} \mathrm{C}$. The $\mathrm{x} / \mathrm{y}$ notation represents the DPW/HDPE w/w ratio

Parameters

\begin{tabular}{ll} 
Blends ratio of DPW/ HDPE & $60 / 40$ \\
\hline Yield stress (MPa) & 45 \\
Ultimate stress $(\mathrm{MPa})$ & 50 \\
Modulus of elasticity $(\mathrm{GPa})$ & 1.8 \\
Density $\left(\mathrm{kg} \backslash \mathrm{m}^{3}\right)$ & 961.6 \\
Energy $(\mathrm{J})$ & 3.895 \\
Cross section exact area $\left(\mathrm{mm}^{2}\right)$ & $9.95 * 4.66$ \\
Impact energy $\left(\mathrm{KJ} / \mathrm{m}^{2}\right)$ & 84 \\
\hline
\end{tabular}


Figure 5 shows the Von-Misses stresses for presented foot is from observing the maximum VonMisses stress as $28.978 \mathrm{MPa}$ at the adapter as follow in Fig. 2 and the minimum value was $3.0562 \times 10^{-9}$ MPa at non-articulated foot of HDPE and DPW.

The results in Fig. 3 were observed as the maximum value of strain and the maximum region of failure. The maximum values of strain in the foot of HDPE and DPW were 0.0073236 .

Comparing the results of stress on the nonarticulated prosthetic foot from ANSYS with the results of a human foot from A AQUS, Young's modulus and Poisson's ratio of the cartilage ligaments and the plantar fascia were selected from the literature, Table 2 (Ozen et al., 2013).

Table 2: Material properties and element types of the anatomical parts of the finite element model (Ozen et al., 2013)

\begin{tabular}{lllll}
\hline Component & Young's modulus $(\mathrm{MPa})$ & Poisson's ratio & Element type & ${\text { Cross sectional }\left(\mathrm{mm}^{2}\right)}$ \\
\hline Bones & 7300 & 0.3 & 3D-tetrahedral & \\
Soft tissue & Hyper elastic & & 3D-tetrahedral & \\
Cartilage & 10 & 0.4 & 3D-tetrahedral & \\
Ligaments & 260 & 0.4 & Tension-only truss & 18.4 \\
Plantar fascia & 350 & 0.4 & Tension-only truss & 58.6 \\
\hline
\end{tabular}

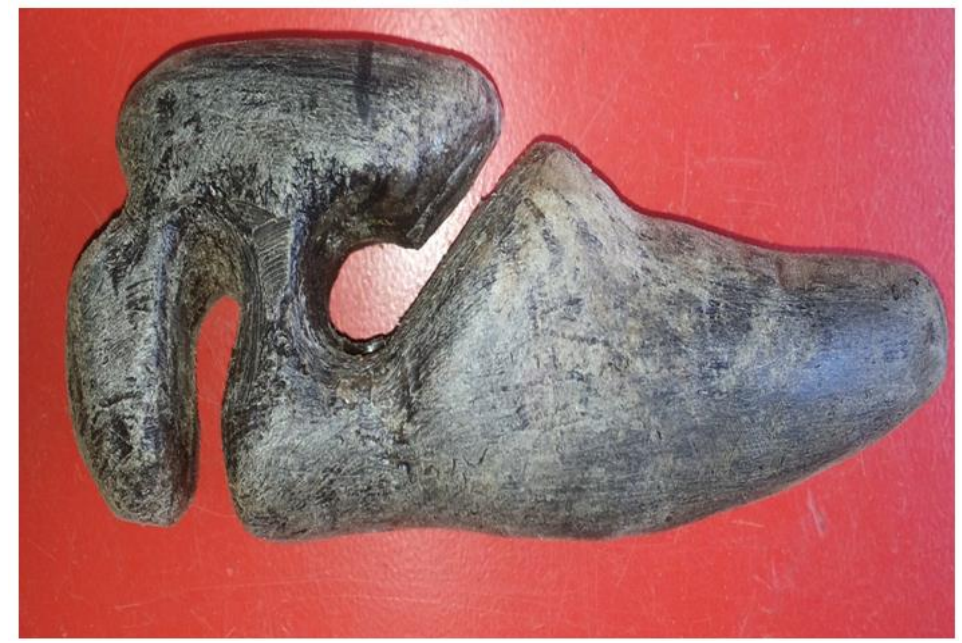

Fig. 1: The injection foot blended of (DPW+HDPE)

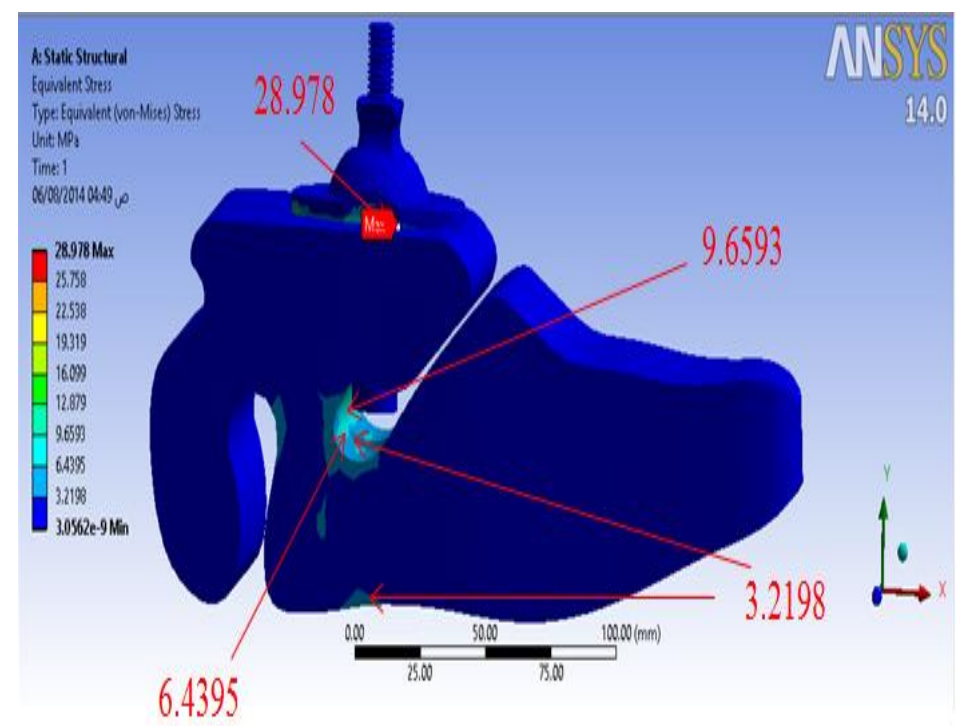

Fig. 2: Von-Misses stresses along the non-articulated foot of (HDPE + LLDPE) 


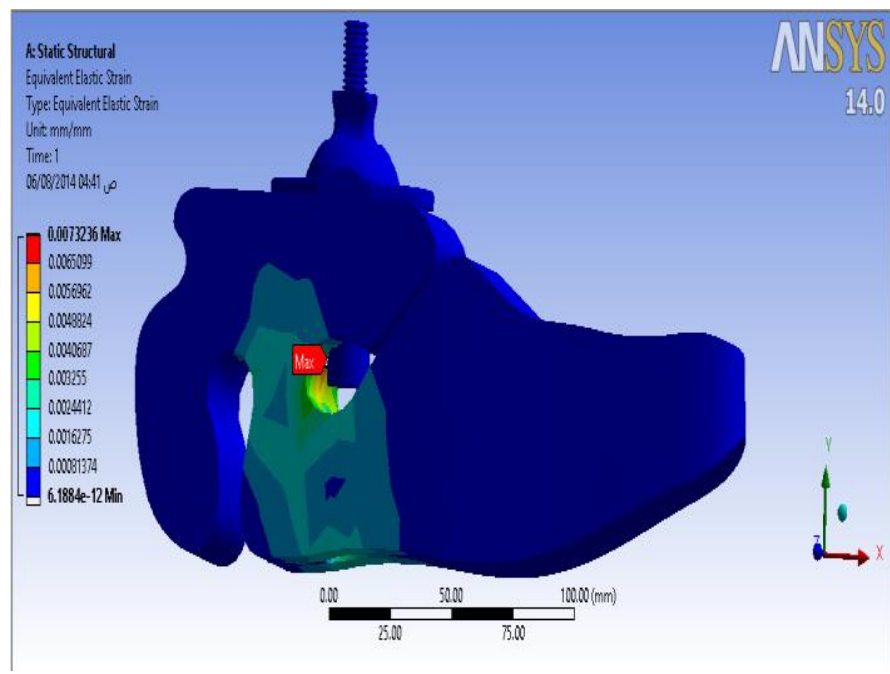

Fig. 3: Von-Misses strain along the non-articulated foot of (HDPE + LLDPE)

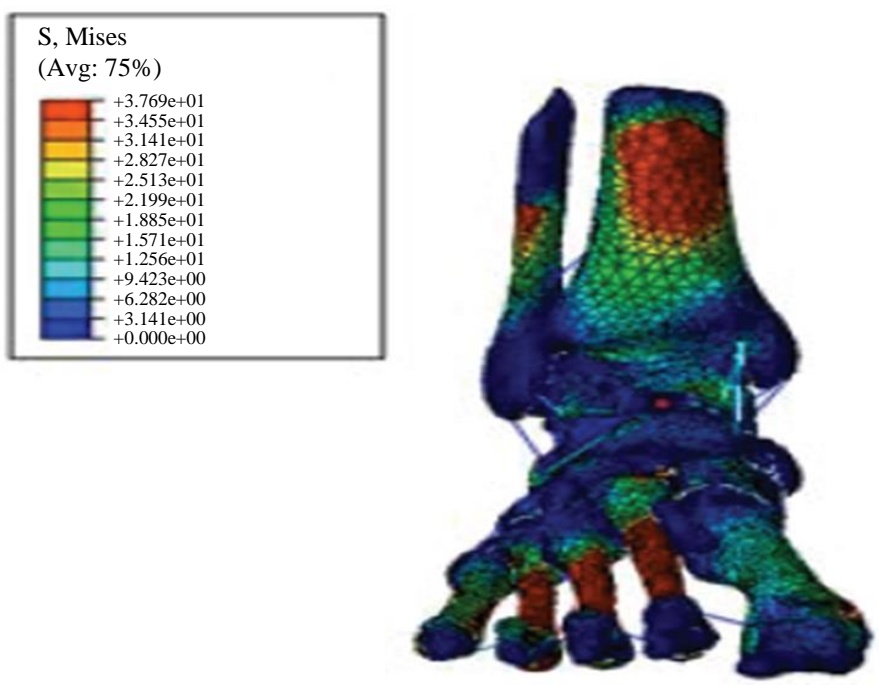

Fig. 4: Von Mises stress distribution of normal foot (Ozen et al. 2013)

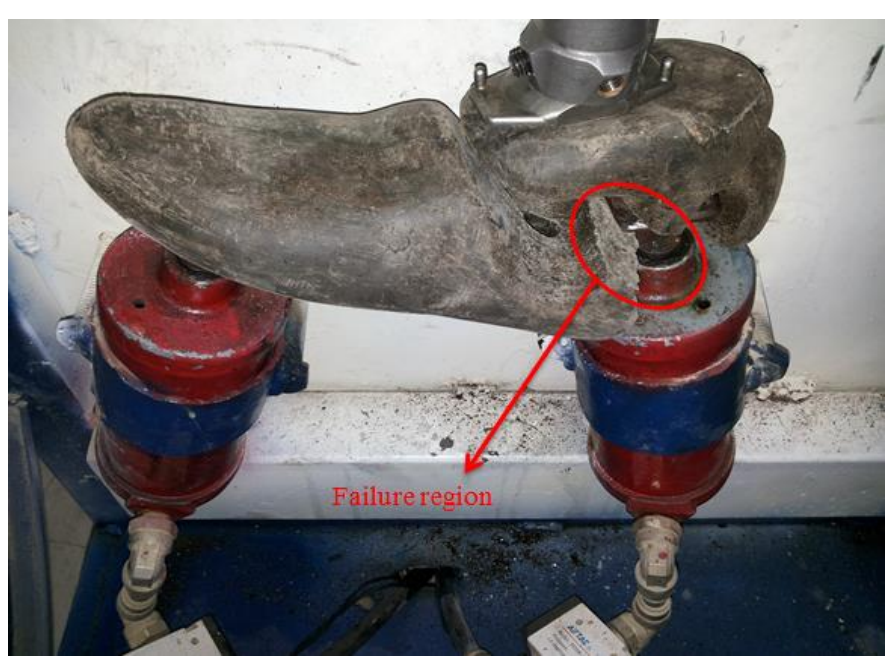

Fig. 5: Failure region in non-articulated foot (HDPE + LLDPE) Apparatus of Kadhim K. R 
The predicted Von-Misses stress distributions of bony structures for both models are given in Fig. 4. Regarding joint stress distributions, for an average prosthetic foot, we predict a peak Von-Misses stress of about 6.766 MPa (Ozen et al., 2013), while for prosthetic foot of HDPE and DPW the peak value was 9.6593.

This study was to generate models of normal foot, soft tissues, by using CT images and MIMICS (Materialize) software and SOLIDWORKS software then export this model into ABAQUS codes (Ozen et al., 2013).

\section{Fatigue Foot Tester Results}

The durability and fatigue characteristics of the prosthetic foot are very important when deciding which type of prosthetic foot to prescribe for a particular patient. The fatigue tester was suitable for this investigation as it applied forces approximating ground reaction forces for the normal walking cycle (Van Rooyen, 1997). In order to have a realistic assurance of the prosthesis' durability and long-term performance, cyclic loading tests must be performed on the foot. A previous senior design team built an experimental fatigue tester. The machine consists of a frame, two pneumatic pistons and a control box that commands solenoid valves to allow air pressure into the cylinders. In order to determine the validity of the non-articulated foot fatigue tester in comparison to other testers currently being used, the industry standard $\mathrm{SACH}$ foot was tested in one of the test stations in order to determine its time failure.

The SACH foot removed from the tester at 896,213 cycles was placed on the tester within a few months of manufacturing. This may indicate the material degradation is a factor in the life expectancy of $\mathrm{SACH}$ feet; however, further testing would have to be undertaken. The new design of non-articulated foot failure occurred in one specimen at 1,049,135 cycles for the foot that manufactured from the blended of $60 \%$ of LLDPE and $40 \%$ of HDPE.

This study was investigated by ANSYS Work bench where it's noted that the failure region in the experimental work was the same failure region in this program as shown in Fig. 6. Figure 5 refers to the real region of failure.

\section{Dorsiflexion}

Figures 7 and 8 show the result of the dorsiflexion angle respectively for $\mathrm{SACH}$ foot, non-articulated foot of HDPE and DPW.

The dorsiflexion angles were obtained using a digital camera. The maximum dorsiflexion angles for normal human foot, $\mathrm{SACH}$ foot and non-articulated foot are recorded.

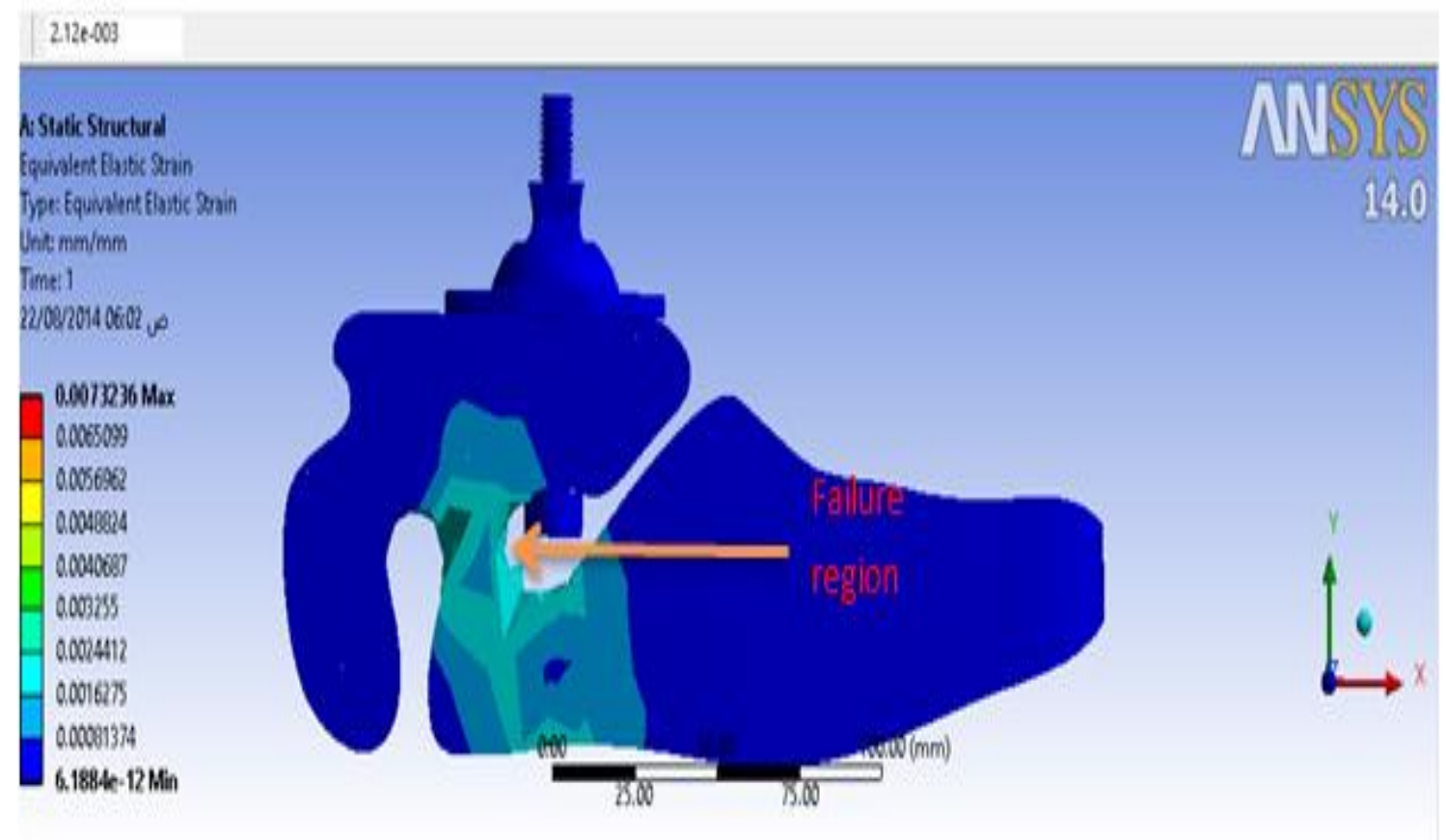

Fig. 6: Failure region in non-articulated foot (HDPE + LLDPE) by ANSYS program 


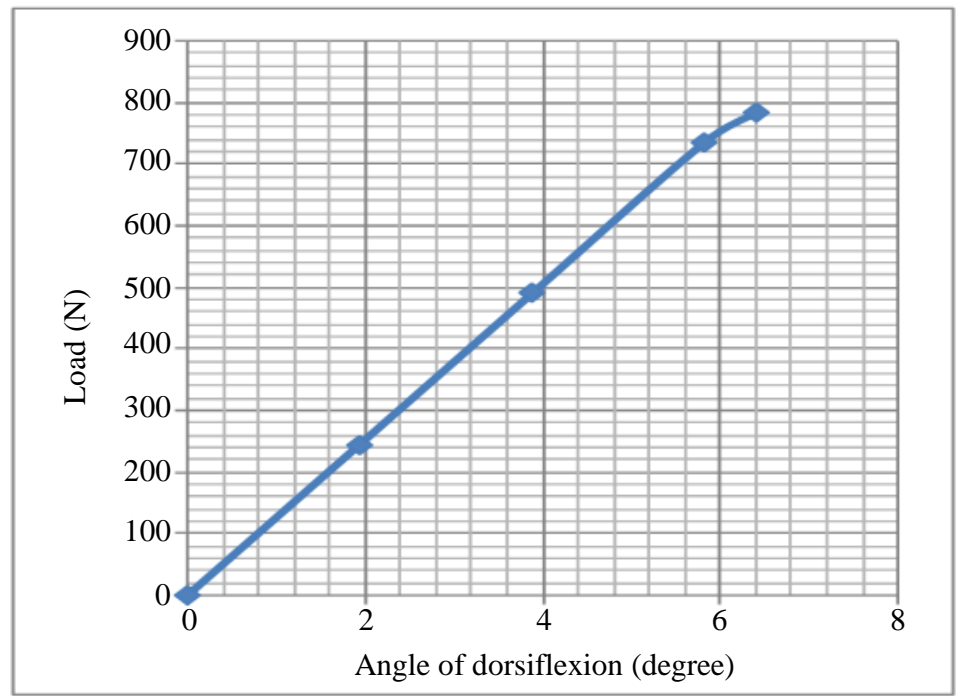

Fig. 7: Experimental load with dorsiflexion angle for $\mathrm{SACH}$

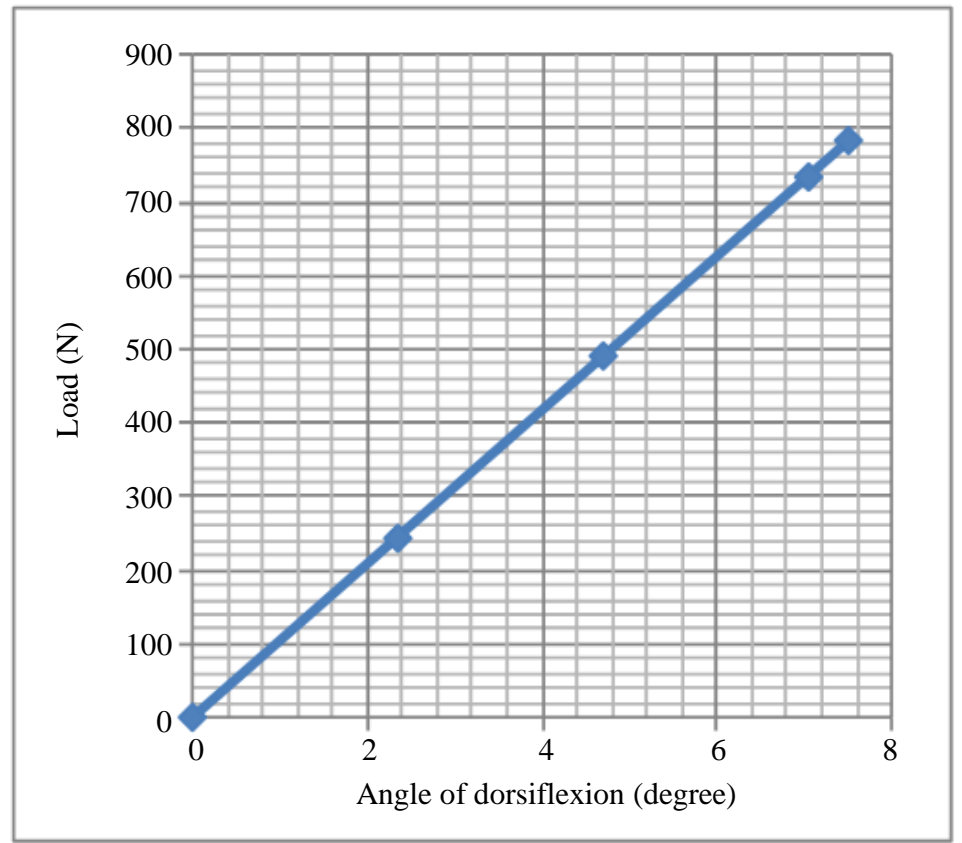

Fig. 8: Experimental load with dorsiflexion for non-articulated design foot of (HDPE + DPW)

\section{Conclusion}

In this study, two different composite materials HDPE and LLDE composites have been developed. The preparation has been done via mold injection. The mechanical properties including impact energy and tensile strength which yield stress, ultimate stress and modulus of elasticity. The specific conclusions of the study are that it showed the yield and ultimate stresses significantly increased by sixty and forty-four percent frequently with mixed blends of forty grams HDPE with sixty grams DPW. Overall, it was o served that the modulus increased by eighty percent compared with pure HDPE and slightly decreased in impact energy by one percent. Further increases in the content caused negligible influences on the stress at break of the materials, which indicated a low interfacial interaction between the polymer and the filler. Generally, the results obtained in this study recommend using these materials for the prosthetics.

From the results obtained both theoretically and experimentally the following conclusion can be drawn: 
1. Using the properties of composite materials of HDPE and DPW for manufacturing the flexible nonarticulated foot gives high dorsiflexion angle and long fatigue life

2. The dorsiflexion angle for the non-articulated foot is greater than that of the $\mathrm{SACH}$ foot, so it may give a bend up to an acceptable limit

3. Lengthening the supporting keel along the whole length of the non-articulated foot gives the best stability to gait profile and long fatigue life

4. The special design with a slotted region on the upper side of the non-articulated foot makes an increment in dorsiflexion angle so it leads to more flexibility in gait profile

5. The non-articulated HDPE and DPW foot is compared with the SACH foot in cost and weight, the cost of non-articulated foot is lower than that of the other by more than eighty percent and the new weight is lighter by about $51.33 \%$. That would be more comfortable for the patient

\section{Acknowledgement}

The author gratefully acknowledge the contributions of Dr. Saad Al-kafaji, Ministry of Science and Technology for his work on the original version of this document.

\section{Author's Contributions}

Hasan Saad Mohammed: Design, Manufacturing, and test this study, wrote this paper, funded this work.

Jasim Mohammed Salman: Justify and check this paper.

\section{Ethics}

Hereby, I'm Hasan Saad Mohammed consciously assure that for the manuscript Design and Modeling the Prosthetic Foot from Suitable Composite Materials the following is fulfilled:

1. This material is the authors' own original work, which has not been previously published elsewhere.

2. The paper is not currently being considered for publication elsewhere

3. The paper reflects the authors' own research and analysis in a truthful and complete manner

4. The paper properly credits the meaningful contributions of co-authors and co-researchers

5. The results are appropriately placed in the context of prior and existing research

6. All sources used are properly disclosed (correct citation). Literally copying of text must be indicated as such by using quotation marks and giving proper reference
7. I have been personally and actively involved in substantial work leading to the paper and will take public responsibility for its content and Jasim Mohammed Salman was consultant

The violation of the Ethical Statement rules may result in severe consequences.

I agree with the above statements and declare that this submission follows the policies of Solid State Ionics as outlined in the Guide for Authors and in the Ethical Statement.

\section{References}

AlMaadeed, M. A., Kahraman, R., Khanam, P. N., \& Madi, N. (2012). Date palm wood flour/glass fi re reinforced hybrid composites of recycled polypropylene: Mechanical and thermal properties. Materials and Design, 42, 289-294.

George, T.A. 1984. Shreve's Chemical Process Industries, 5th ed. McGraw-Hill Inc; New York. pp. 656-657.

Kadhim, K. (2007). Resan Al-Kinani, "Analysis and Design Optimization of Prosthetic below Knee" $\mathrm{Ph}$. D., College of Engineering, Technology University.

Mariam, A. Al Maadeed, Zuzana Ngellov, Ivica Janigova and Igor Krupa (2014): Improved mechanical properties of recycled linear lowdensitypolyethylene composites filled with date palm wood powder. Materials and Design 58, 209-216.

Ogah, A. O., \& Afiukwa, J. N. (2012). The effect of linear low density polyethylene (LLDPE) on the mechanical properties of high density polyethylene (HDPE) film lends. Int J Eng Manag Sci, 3(2), 85-90.

Ozen, M., Sayman, O., \& Havitcioglu, H. (2013). Modeling and stress analyses of a normal foot-ankle and a prosthetic foot-ankle complex. Acta of ioengineering and iomechanics, 15(3).

Van Rooyen, J. (1997). Material fatigue in the prosthetic SACH foot: Effects on mechanical characteristics and gait (Doctoral dissertation, La Tro e University).

Zeng, Y. (2013). Design and testing of a passive prosthetic ankle with mechanical performance similar to that of a natural ankle.

Zhang, X. S., Guo, Y., An, M. W., \& Chen, W. Y. (2013). Analysis of kinematic data and determination of ground reaction force of foot in slow squat. Acta Mechanica Sinica, 29(1), 143-148. 